\section{Management and strategy}

\section{Abraham Ortiz Miranda}

Universidad de Los Andes

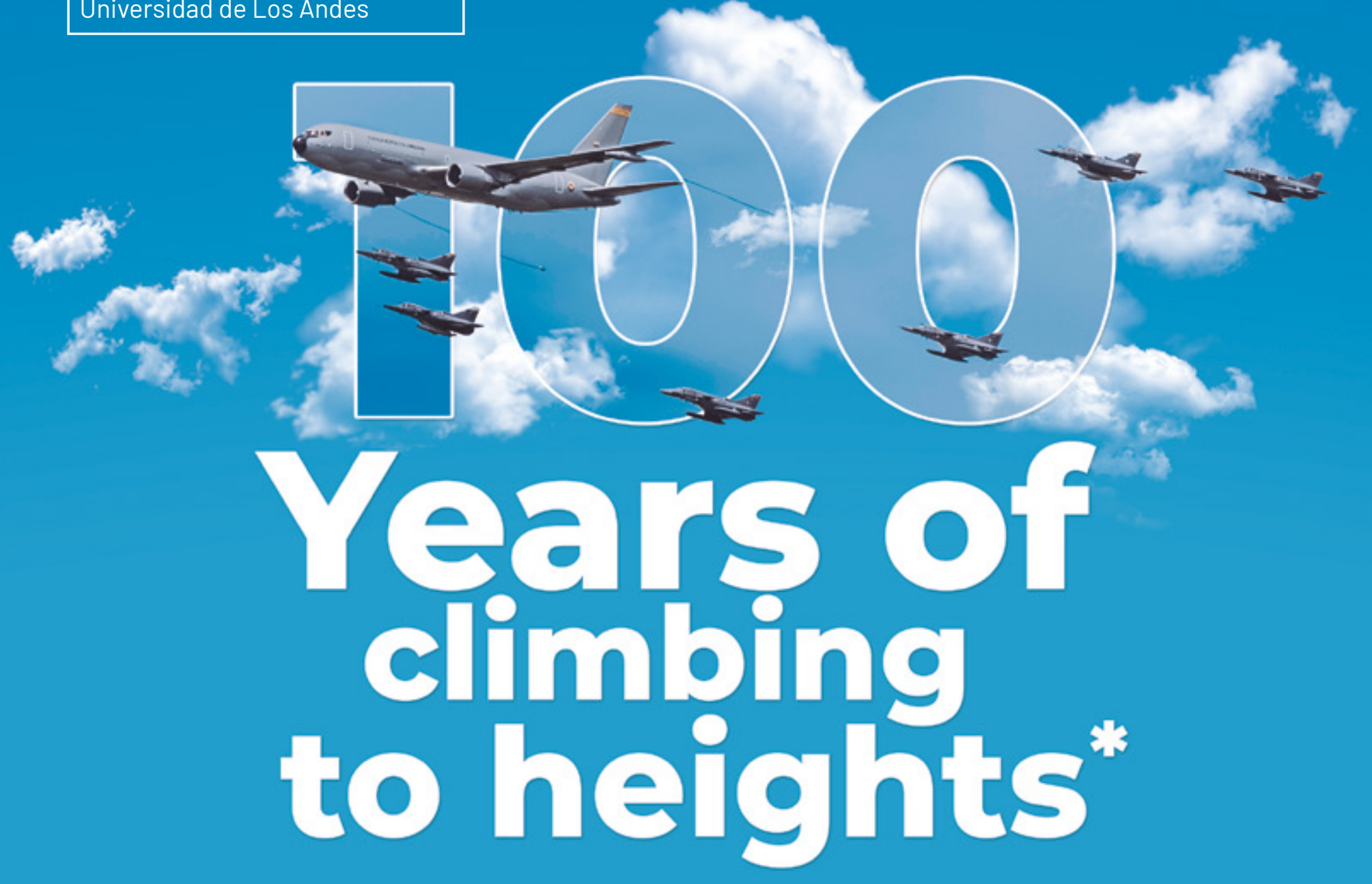

GOPEN ACCESS CIENCIA Y PODER AÉREO

Enero-Junio de $2010 /$ Colonb-2

Citación: Ortiz, A. (2019). 100 años de ascensión a las alturas. Ciencia y Poder Aéreo, 14 (1), 20-41. Doi: https://doi.org/10.18667/cienciaypoderaereo.620

\section{Abraham Ortiz Miranda}

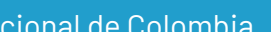

estudiante de Maestría en Ciencia Politica - Universidad de los Andes.

Wisualizador/generarCurriculoCv.do?cod_rh=000009538

CURAC: hitps://scienticolicicins

ser=oyXzCmwAAAAJ\&hl=es

Doi: https://doi.org/10.18667/cienciaypoderaereo.620 *Article of Reflection taken from research. Attached to the Research Group "Análisis de Contexto - Context Analysis" endorsed by the
Universidad de los Andes and the Colombian Air Force "Ciencia y Poder Aéreo", (CIPAER, by its Spanish acronym). Colombian Air Force
ABSTRACT

The entire country has witnessed 100 years of history when looking at the sky. One hundred years of evolution and development in which the Colombian Air Force has been the inventor of great achievements, feats that only fulfill the sole purpose of safeguarding Colombian airspace. However, this centennial must be seen through a focus that allows glimpsing the completeness and complexity of the Force from those significant milestones that actually open the door to the universe of knowledge of it. Therefore, factors such as technological development, the generation of new knowledge the versatility and flexibility involved in the application of air power, and the professional development and constant training of military and non-uniformed personnel are some Milita predominant factors for the to fulfill its constitutional duty.

For such purpose, this article has three sections which aim to briefly analyze both from the genesis of the Institution to its present times. Two of them are the sets of structures of temporary development that have defined one hundred years of the Force, being such dynamics those that characterize the three headings of this reflection: Initially, the aforemenved in processes of professiona development and constessionationed military entity was invol- formed personnel to face multiple transnational threats. As a second stage, such air military power began to develop new knowledge that has allowed it to expand its institutional capabilities in terms of versatility and flexibility. This has had a significant impact at the international level insofar as these conglomerates, which are still in force today, have helped this military entity transcend the various national borders; this work has had the objective of transforming and strengthening its different forms of intersubjective relationship, which has allowed this State organism to support both different organism to support both different tarian basis as well as scientific research at the same time.

\section{KEY WORDS:}

Technological Development, Colombian Air Force, Temporary Structures, Generation of Knowledge, Air Power, Professional Development. 


\section{Gestião y Estratégia}

\section{Abraham Ortiz Miranda}

Universidad de Los Andes

$2 x$

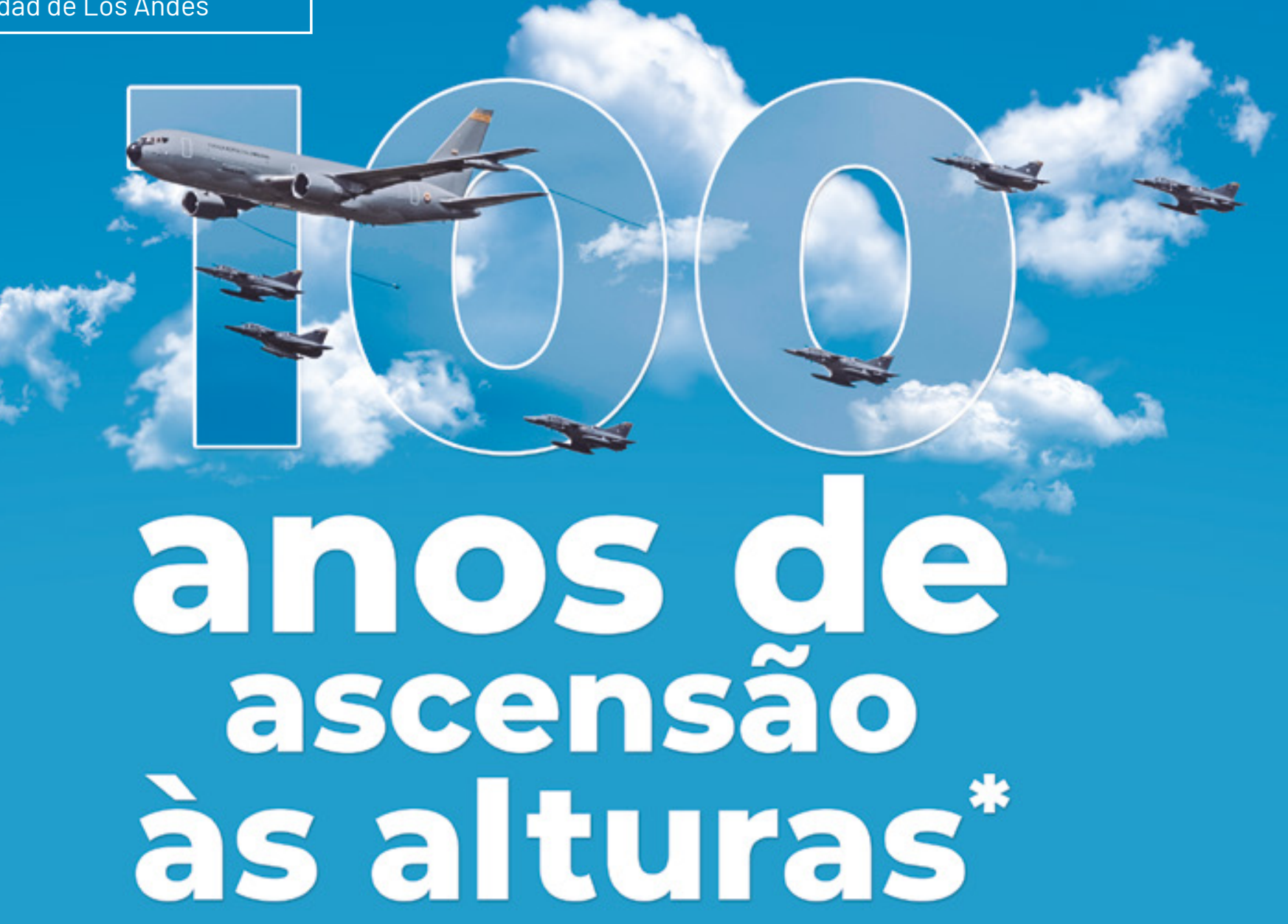

Gopen ACCESS CIENCIA Y PODER AÉREO

Enero-Junio de 2019/Colombia/ Pp. 20-41

Citación: Ortiz, A. (2019). 100 años de ascensión a las alturas. Ciencic y Poder Aéreo, 14 (1), 20-41. Doi: https://doi.org/10.18667/cienciaypo

Abraham Ortiz Miranda

Anal de Colombia,

estudiante de Maestria en Ciencia Politica - Universidad de los Andes.

(a)

Doi: https://doi.org/10.18667/cienciaypoderaereo.620

* Artigo de reflexão derivado da investigação. Ligado ao Grupo de Pesquisa "Análise de contexto" avalizado pela Universidade dos Andes

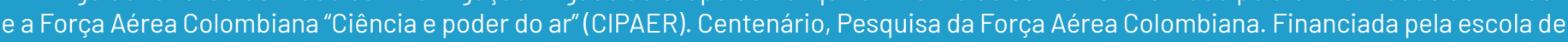
graduação da Força Aérea Colombiana.
RESUMO:

São 100 anos de história evidenciados para um país enteiro ao Olhar para o ceu. Cem anos de evolução e desenvolvimento nos quais a Força Aerea Colombiana tem sido a inventora de grandes proezas a fim de cumprir com o único propósito de proteger 0 espaço aereo colombiano. No entanto, esse centenario deve ser visto atraves de um foco que nos permite vislumbrar a completude e a complexidade da Força, a partir desses grandes marcos que realmente abrem a porta para o universo de seu conhecimento. Assim, fatores como desenvolvimento tecnológico, geracão de novos conhecimentos, versatildade e flexibilidade na aplicaça do poder aéreo, profissionalizaça e treinamento constante de mill-

tares e não-uniformizados, são lguns dos fatores predominantes que a Instituição Militar aqui descrita necessita para cumprir seu dever constitucional.

Para esse fim, o presente artigo abrange três seções nas quais se pretendem analisar, apenas a partir da genese da Instituição ate seus tempos atuais. Existem dois conjuntos de estruturas de desenvolvimento temporário que marcaram os cem anos da Força Armada sendo tais dinâmicas as que caracterizam as três posições da presente reflexão: no inicio, a entidade militar acima descrita foi preconizada para processos de profissionalizacão treinamento constante de seus milita

res e não-pessoal uniformizado

ara enfrentar ás várias ameaças transnacionais. Numa segunda fase, o poder aéreo começou a desenvolver novos conhecimentos que the permitiram expandir suas capacidades institucionais em termos de versatilidade e flexibilidade. 0 acima exposto, tem tido grande impacto a nivel internacional, na medida em que tais conglomerados, ainda hoje em vigor, têm sido essenciais para esta entidade castrense possa transcender as sortidas fronteiras nacionais. Este trabalho teve como objetivo transformar e fortalecer suas diferentes formas de relacionamento intersubjetivo, o que permitiu ao órgão do Estado, dar muito apoio a diferentes nac̃os, tanto de maneira humanitária quanto de maneira científica.

\section{PALAVRAS-CHAVE:}

desenvolvimento tecnológico, Força Aérea Colombiana, estruturas temporárias, geração de conhecimento Força Aérea, profissionalização. 


\section{Sección Gestión y Estrategia}

\section{Abraham Ortiz Miranda}

Universidad de Los Andes

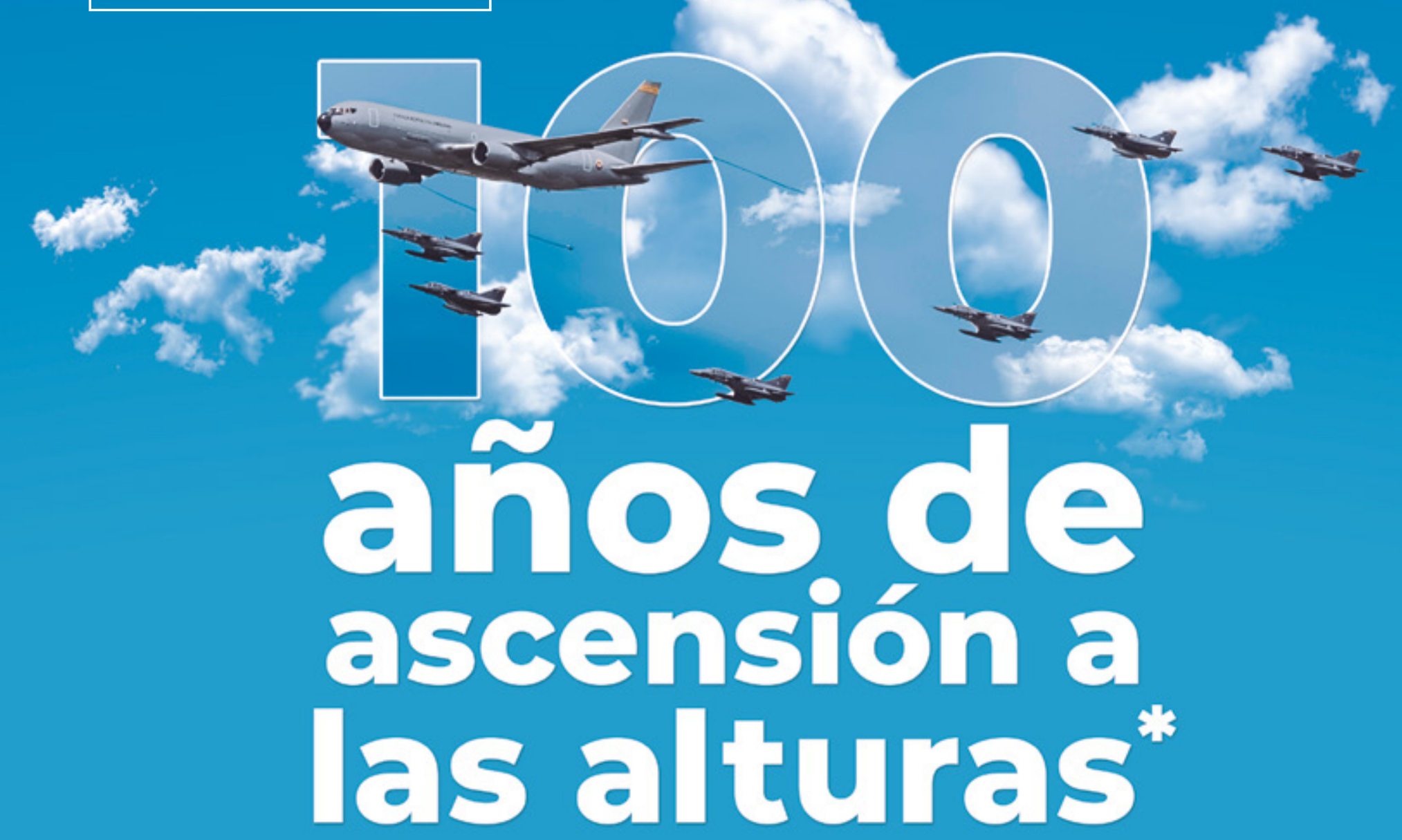

GoPEN ACCESS CIENCIA Y PODER AÉREO

(2)

Citación: Ortiz, A. (2019). 100 años de ascensión a las alturas. Ciencia y Poder Aéreo, 14 (1). 20-41. Doi: https://doi.org/10.18667/cienciaypod_

Abraham Ortiz Miranda

estudiante de Maestria en Ciencia Política - Universidad de los Andes.

aortizmiranda@gmail.com ORCID: https://orcid.org/0000-0002-7169-1529

(2)

Doi: https://doi.org/10.18667/cienciaypoderaereo.620

* Artículo de reflexión derivado de investigación. Adscrito al Grupo de Investigación "Análisis de Contexto" avalado por la Universidad de Ios Andes y la Fuerza Aérea Colombiana "Ciencia y Poder Aéreo" (CIPAER). Investigación Centenerio Fuerza Aérea Colombiana. Financiado por la Escuela de Postgrados de la Fuerza Aérea Colombiana.

RESUMEN

Son 100 años de historia los que ha evidenciado el país entero al mirar al cielo. Cien años de evolución y desarrollo en los que la Fuerza Aérea Colombiana ha sido inventor de grandes gestas, hazañas estas que sólo cumplen el único fin de salvaguardar el espacio aéreo colombiano. Sin embargo, tal centenario debe ser visto a través de un foco que permita vislumbrar la completitud y complejidad de la Fuerza a partir de aquellos grandes hitos que realmente abran la puerta al universo del conocimiento de la misma. Es asi que factores tales como el desarrollo tecnológico, la generación de nuevo conocimiento, la versatilidad y flexibilidad presentes en la aplicación del poder aéreo la profesionalización y constante formación del personal militar y

no uniformado, son algunos de los actores preponderantes para que la Institución Castrense aqui reseñada pueda cumplir con su deber constitucional.

Para tal fin, el presente artículo cuenta con tres secciones en las que se pretenden analizar, someramente, tanto desde la génesis de la Institucion como hasta sus tiempos actuales. Dos son los conjuntos de estructuras de desarrollo temporal que han marcado los cien años de la Fuerza, siendo tales dinámicas las que caracterizan los tres acápites de esta reflexión: en un princites de esta cionada entidad castrense se vio lo nalización y constante formación de su personal military nouniformado para enfrentar múltiples amenazas trasnacionales. Como segundo estadio, tal poder militar aereo empezo a desarrollar conocimiento novedoso que le ha permitido ampliar sus capacidades institucionales en cuanto a versatilidad y flexibilidad se refiere. Lo anterior, ha tenido gran impacto a nivel internacional en la medida que dichos conglomerados, aun hoy vigentes, han coadyuvado para que esta entidad castrense trascienda las variadas fronteras nacionales; esta aludida labor ha tenido como objetivo el transformar y afianzar sus diferentes formas de relación intersubjetiva, lo cual ha permitido que este organismo del Estado pueda apoyar tanto a distintas pueda apoyar mundo de manera huma del como a investigación científica a la par.

\section{PALABRAS CLAVE:}

desarrollo tecnológico, Fuerza Aérea Colombiana, estructuras temporales, generación de conocimiento, poder aéreo, profesionalización.

(c) TERIGHISHESERFI
Los textos publicados en esta revista están sujetos -si no se indica lo contrario- a una licencia de Reconocimiento 4.0 Internacional de CreativeCommons. La licencia completa se puede consultar en https://creativecommons.org/licenses/by/4.0/deed.es_ES.

Aprobado evaluador interno: 15/08/2019 Aprobado evaluadores externos: 30/08/2019 
INTRODUCCIÓN

No es azar que la Fuerza Aérea Colombiana (FAC) conmemore su primer centenario. Institución de heroes que quienes diestros como el ave insignia de la misma el águila arpia, han entregado todo de sí para salvaguardar el espacio aereo colombiano, con elúnico fin de preservar la integridad de nuestro basto y rico territorio nacional.

La conjugación constante que sucede entre las inquietudes de los diferentes mandos de la Fuerza y el ahínco del multipolar persona de la misma, son las variables que han edificado y custodiado la aviación militar colombiana durante sus cien años de historia. El desarrollo tecnológico la generación de nuevo conocimiento, la versatilidad

la flexibilidad presentes en la plicación del poder aéreo, as como la profesionalización y la constante formación del personal militar y no uniformado, han sido algunos de los factores preponderantes para que la Fuerza Aérea Colombiana esté en continuo cumplimiento de su debe constitucional. Cometido puesto en marcha desde el primer dia que decolaron sus aeronaves los cielos patrios.

En el trasegar de la consecución de sus objetivos, la Fuerza Aérea Colombiana ha materializado acciones relevantes para el mantenimiento de la nación, espacios que han permitido visualización de las variables y

os factores anteriormente desritos. Sin embargo, para el presente estudio, la preponderancia y elección de algunos momentos históricos del accionar de la FAC responde a que en ellos se destaca la generación de nuevas vitructuras: de nuevos modus vivendi que gestan excelentes resultados tanto para la Institucion, en un primer estadio, como para el Estado colombiano en un segundo momento (Goberna, 2003, pp. 218-222). De allí que se le sugirió a la mirilla centrarse en aquellos acontecimientos que traspasan las conciencias de los contemporáneos para ser más que una explosión, una llamarada que obnubila a los mismos; a enfocarse en aquellos hitos

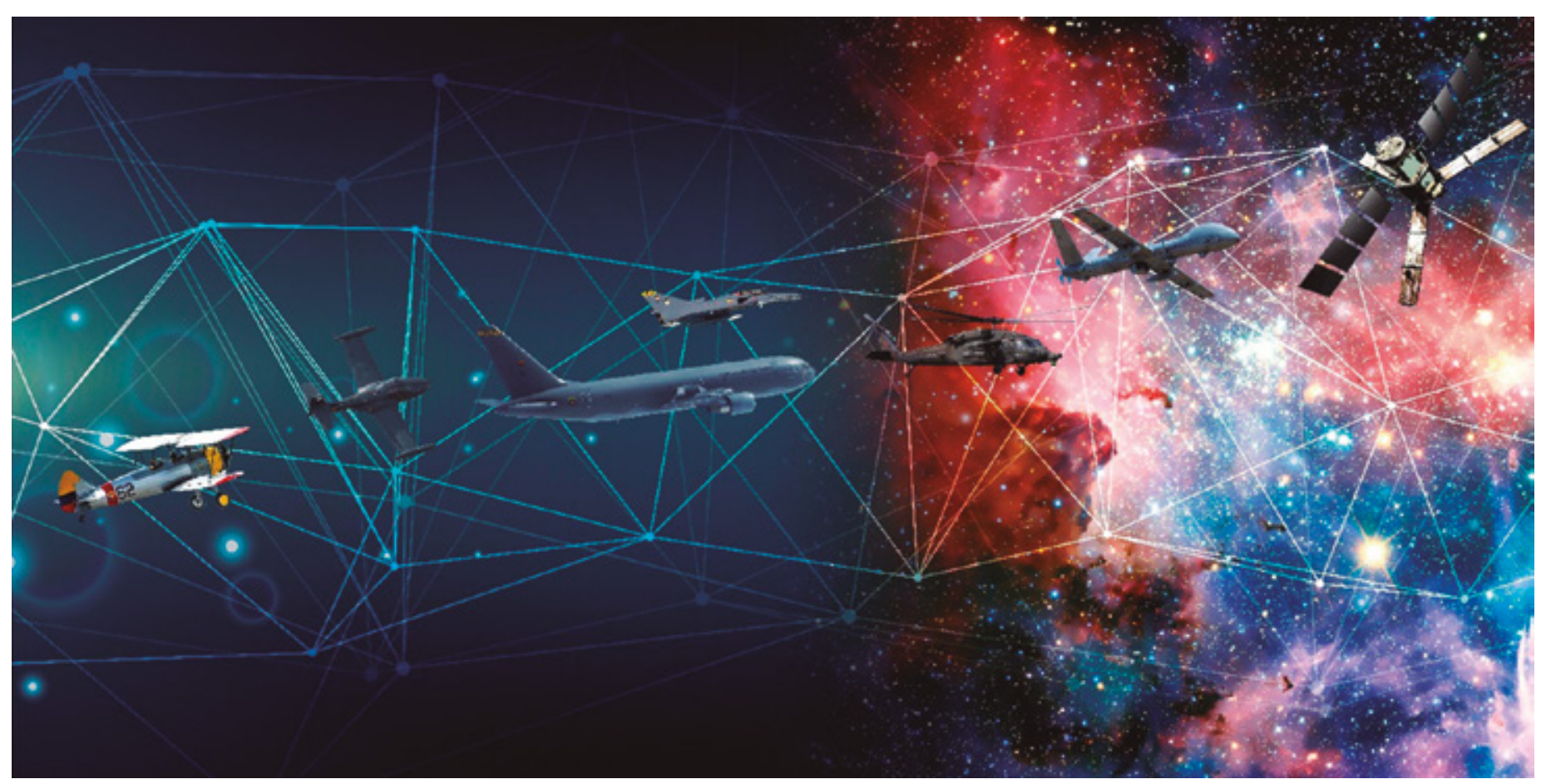

[Diseño de Abraham Ortiz Miranda y Aldemar Zambrano Torres] (Bogotá D.C.. 2017). Archivo de diseños

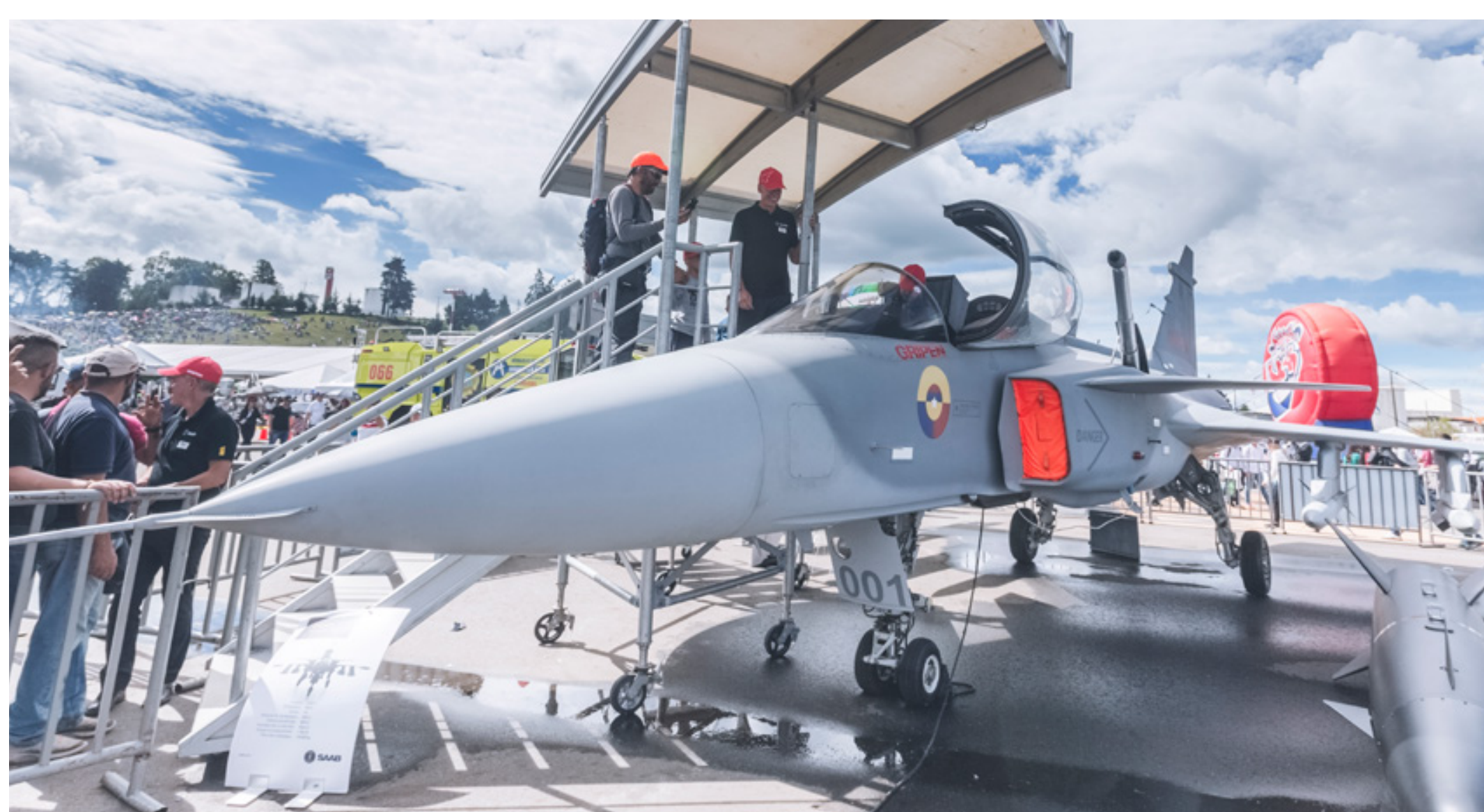

que han dado paso a la conformación de estructuras temporales y que han permitido que la institución trascienda al simple hecho de ser nada más que una organización.

A su vez, tales estructuras se ven enmarcadas en complejas dinámicas temporales que permite explicar las razones de su génesis. Sucesos como el conflicto con el Perú y la Segunda Guerr Mundial dieron a conocer a la nacion colombiana la necesidad de contar con un poder aéreo tecnológicamente desarrollado en razón de sobre guardar la soberanía nacional. Lo anterior, trajo consigo el abandono de toda práctica empírica por parte de personal del vuelo lo cual permitio su cabal especialización.
Partiendo de dicho contexto, en un segundo de estadio, este artículo se concentra en determinar los hechos que causaron el ahondamiento y afianzamiento de las prácticas descritas, las cuales dieron lugar a un nuevo conocimiento sobre las capacidades que han tenido las distintas flotas de aeronaves con las que han contado la Fuerza Aérea Colombiana, para asi interconectar los variados centros de población con las múltiple del país. No fue solamente por medio del desarrollo de ataques estratégicos de precisión con los que la Fuerza coadyuvó para que las regiones del país se interconectaran y recuperaran su paci'Bombardeos de precisión sobre objetivo militares específicamente delimitados estudios bajo el
cho Operacional. zonas periféricas y de difícil acceso fico bienestar, sino que a su vez, la misma ha alcanzado capacidades de transporte aéreo que facilitan la movilidad de la gente, agilizando diversos procesos de intercambio.

En un tercer momento se pretende analizar los alcances que ha tenido la institución castrense, aquí estudiada, a nivel internacional en razón de que la misma ha participado como miembro activo en distintos y trascendentales ejercicios militares. Ejercicios que le han permitido llegar a lugares recónditos de la geografia nacional, a la par que ha podido apoyar diversas labores humanitarias en distintos países del mundo. Finalmente, la conclusión dará cuenta sobre las diversas estructuras temporales que han pervivido durante los cien años de historia de la Fuerza Aérea Colombiana y sus influjos sobre la nación. 


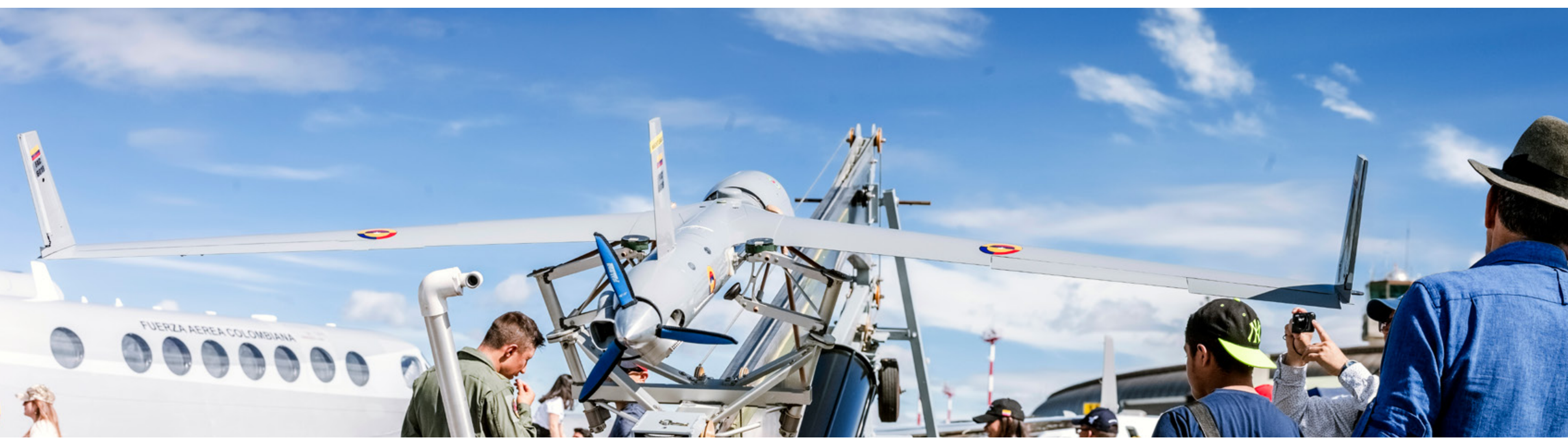

OBJETIVO

Se ha de comprender entonces que el presente artículo trasciende el simple hecho de ser un recuento historico cronológico de los distintos estadios que ha transitado la Fuerza Aére Colombiana hasta el día de hoy. Por lo tanto, se planteo como objetivo: profundizar en los hitos históricos de la FAC, con el fin de determinar aquéllos puntos temporales que, si bien pudieron gestarse de manera disruptiva o como secuencia de un proceso lógico de desarrollo, generaron continuidades históricas las cuales han permeado las prácticas de la Institución durante estos cien años.

\section{MARCO CONCEPTUAL}

Relegándose a un segundo plano tanto personajes como actores que han alcanzado reconocimiento interior del ente castrense aéreo (entre ellos, aeronaves o determinadas infraestructuras aéreas), prostructuras aereas), preminencia de esta investigación partira de la comprensión de las tóricas como aquéllas actividades humanas que presentaron un novedoso talante y que las hicieon suficientes para ser adoptadas como practicas rutinarias en las comunidades donde se gestaron y desarrollaron. Si bien se conmemoran ciertos sucesos clave interior de la Institución lo crucia aquí no son ellos como tales, sino las prácticas que dichos acontecimientos acarrearon, los cuales han trascendido en todo el trasegar de la Fuerza Aérea Colombiana, debido a que son ellas las que nos presentan las bases dialécticas para la comprensión de la conformación de las estructuras temporales antes enunciadas ${ }^{2}{ }^{3}$

2 Para el presente estudio, son conceptos sinónimos tanto continuidad histórica y con3 Para el lector interesado en una reseña histórica de la Fuerza Aérea Colombiana, que puntualice en hechos, sujetos y eventos conmemorativos, puede revisar la bibliografía aquí utilizada, en especial el Años en los Cielos Patrios.
MARCO TEÓRICO

Si bien realizar una narrativa absoluta de la historia que ha forjado la Fuerza Aérea Colombiana durante un siglo de existencia es una tare apoteosica y casi imposible, el adelantar un acercamiento aproximado sobre la misma significa generar un conocimiento eficaz y comprensible de sus estructuras temporales, de los derroteros que ha experimentado, y de sus valores pretéritos y tradicionales a razón de que una entidad castrense como la aquí estudiada, como lo menciona Goberna (2003), "es siempre un pasado, de este modo, un cierto pasado vivo" (p. 218). Sin negar, además, que son las continuidades temporales construidas y establecidas a través de un siglo de existencia las que han dado paso a una estructura, a un indudable "ensamblaje, una arquitectura; pero, más aún, una realidad que el tiempo tarda enormemente en desgastar y en transformar Braudel, 2006, p. 8), al interior de la Fuerza Aérea Colombiana.

Es en dicho ensamblaje donde reside la importancia de los acontecimientos que traspasan las conciencias de los contemporáneos para ser más que una explosión o una llamarada que los obnubila, tal y como se menciono anteriormente Al ser testigo de movimientos muy profundos, se llega a la conclusión de que los mismos deben estar cargados de una serie de significaciones y reciones que significaciones de presentar consecuencias de tal mesnitad consecuencias de reloj de tiempo de Fernand Braudel: "primen de del. "primero, del acontecimiento estructuctura, $y$, despues, de las acontecimiento" (2006, p. 4, 32).

En otras palabras, son de suma importancia sólo los hitos aeroespaciales de la entidad que representan un tipo de acontecimiento que entra en dialéctica con aquella arquitectura que le rodea para romper con "los viejos ciclos y 


\section{DIFICIL DECOLAR}

con las tradicionales costumbres" (Goberna, 2003, p. 218) del mundo castrense. Son únicamente aquellas intervenciones que realmente señalan un cambio, una nueva fase o un nuevo modo de estar que destacan por si mismas, por motivo de gestar nuevas estructuras que se vuelven casi imperecederas al trasegar del tiempo relacionando el pasado con el presente en "un continuo ir y venir" (Goberna, 2003, p. 219). Por consiguiente, se debe tener en la mirilla únicamente aquellos hitos trascendentales que realizó la Fuerza Aérea Colombiana y con los cuales logró la construcción de realidades que han tenido una prolongación temporal extensa a pesar de que las mismas muten imperceptible y lentamente; esta forma sobresalgan en la institución "las grandes perma institucion, "las grandes permanencias o semipermanencias, tanto (Goberna, 2003, pp. 221-222).

A partir de lo anterior, se estableció como ruta de trabajo una investigacion de caracter cualitativo de orden historico que a partir de la reconstrucción de diversos hechos del pasado de la Fuerza Aérea Colombiana, pre tende encontrar estructuras que permitieran explicar la necesidad del establecimiento y la consolidación de una institución castrense como lo es la Fuerza Aére Colombiana, resaltando en todo momento sus cambios y continuidades temporales.
Los roles que le fueron concedidos a la Fuerza Aérea Colombiana florecieron por motivo de la necesidad imperiosa que presento Estado Colombiano princio Siglo XX de proyo a principio de Siglo $X X$ de proyectarse como un y progresista. Influenciadas las administraciones de la época po los positivos resultados presentados por la aviación militar durante el desarrollo de la Primera Guerra Mundial y por el menester de la reconstitución nacional después de la finalización de la Guerra de los Mil Días, el presidente José Vicente Concha decretó y nombró, el 7 de septiembre de 1916, a la primera comisión de militares que tendrían como objetivo cursar en el exterior la para entonces novedosa fase de vuelo. No nove tal sueño de volar se volcó en re tal sueno de volar se volcó en reacuando el presidente de la epoca Marco Fidel Suárez cró la época, Marco Fin la Ley 126, de ese mismo año, la Escuela Miltar de Aviación, alma mater de los pilotos militares de

Si bien a la Fuerza Aérea Colombiana se le presentaron obstáculos en sus inicios para establecerse como cuerpo castrense de la nación, fue el despliegue de las primeras operaciones aéreas las que le demostraron al país lo trascendental del actuar de la aviación militar en el contexto del sostenimiento de la soberanía. Hechos como el asedio aéreo realizado sobre el bastión de Güepí en el marco del conflicto colombo-peruano fueron los que evidenciaron cómo tan sólo una simple victoria

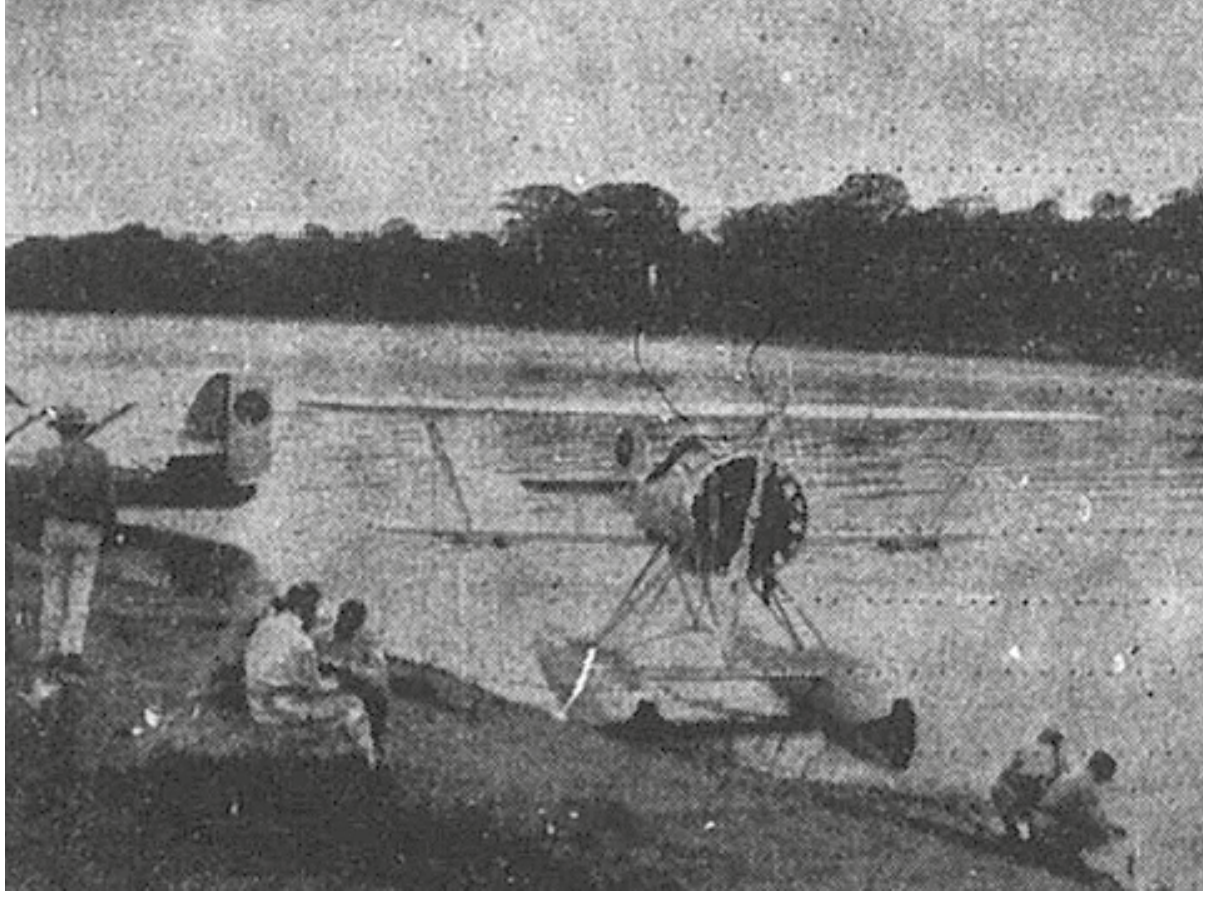

Falcon F-8F sobre el Rio Putumayo. [Fotografía de El Tiempo]. (Bogotá, 1933).
El Tiempo: diario de la mañana. Biblioteca Nacional, Bogotá D.C., Cundinamarca.

decisiva desde el aire puede generar y mantener en paz los territorios de nuestra rica geografia (Villalobos, 1993, pp. 70-72).

En el escenario de operaciones del trapecio amazónico, el triunfo colombiano germinó a razón del proceso de estandarización al que se vio sometida tanto la instrucción como la formación de los aviadores y mecánicos colombianos. Debido a las pugnas territoriales gestadas en el marco de la explotación cauchera de inicios de siglo $X X$, detonante este del conflicto colombo-peruano por motivo de la violación del tratado fronterizo firmado en 1922 por parte del Peru (Palacios, 2002 por 514-517) vuelo primario y el mantenimiento se comenzaron a especializar a tal punto que las prácticas empiricas se abandonaron por completo. Inclusive, se procuró traducir los manuales existentes para aquél tiempo "lo mejor posible al español y elaborar otros, siguiendo el lineamiento de los existentes e incorporando la experiencia que se había adquirido en los años anteriores"(Peña, 2015, p. 30).

Tal versatilidad propia de la aviación militar consistente en allegar y acercar rincones distantes de Colombia en poco tiempo (MADBA, 2013，pp. 62-62, 74), y determinante para la finalización de los enfrentamientos con el Perú, se continuó reflejando en el hecho de la vigilancia especia- 
lizada que realizó la Fuerza Aérea Colombiana en las costas caribeñas durante el desarrollo de la Segunda Guerra Mundial. Para ello, la Institución prosiguió en su camino de desarrollo tecnológico para así seguir liderando el poder aeroespacial en pro de la defensa nacional, renovando sus flotas de aeronaves de aquel entonces por los estables y agiles aviones norteamericanos: Texan AT-6.

El hundimiento de la goleta Resolute a 50 millas náuticas al nordeste de San Andrés y a 35 de Providencia, y el hecho del rompimiento de relaciones que realizó gobierno del entonces presidente Eduardo Santos con los países de

Eje, tuvo como consecuencia que Colombiano organizara patrullajes y vigilancia en el litoral caribe del pais, encargando la realizacion de taltarea en el menor nacional (Forero, 1994, pp. 68-69).

Dichos preceptos fueron los que obligaron el surgimiento y afianzamiento de la aviación militar colombiana de ala rotatoria, gestándose así, de manera sincrónica, la primera Base Aérea de Helicópteros del pais y su correspondiente y prestigiosa Escuela de formación, todo debido al gran número de tales equipos de vuelo adquiridos por el gobierno de aquél tiempo. Tan sólo un año des- pués del advenimiento de la pripuera de ala rotatoria a la Fuerza Aérea Colombiana es que los turbos reactores se toman la institución. A partir de la incursión en la Fuerza del Silver Star T-33 de la Lockheed para el año de 1954, es que la nación entera ingresa a la era del jet, época dorada que daría como resultado la creación del Servicio Aereo a Territorios Nacionales (SATENA), una aerolínea cuya punta de lanza es la integración económica y social de las regiones más apartadas del país, reflejo de la materialización continuada de los objetivos siempre presente en el desenvolvimiento temporal de la FAC (Forero, 1994 pp. 160-163).

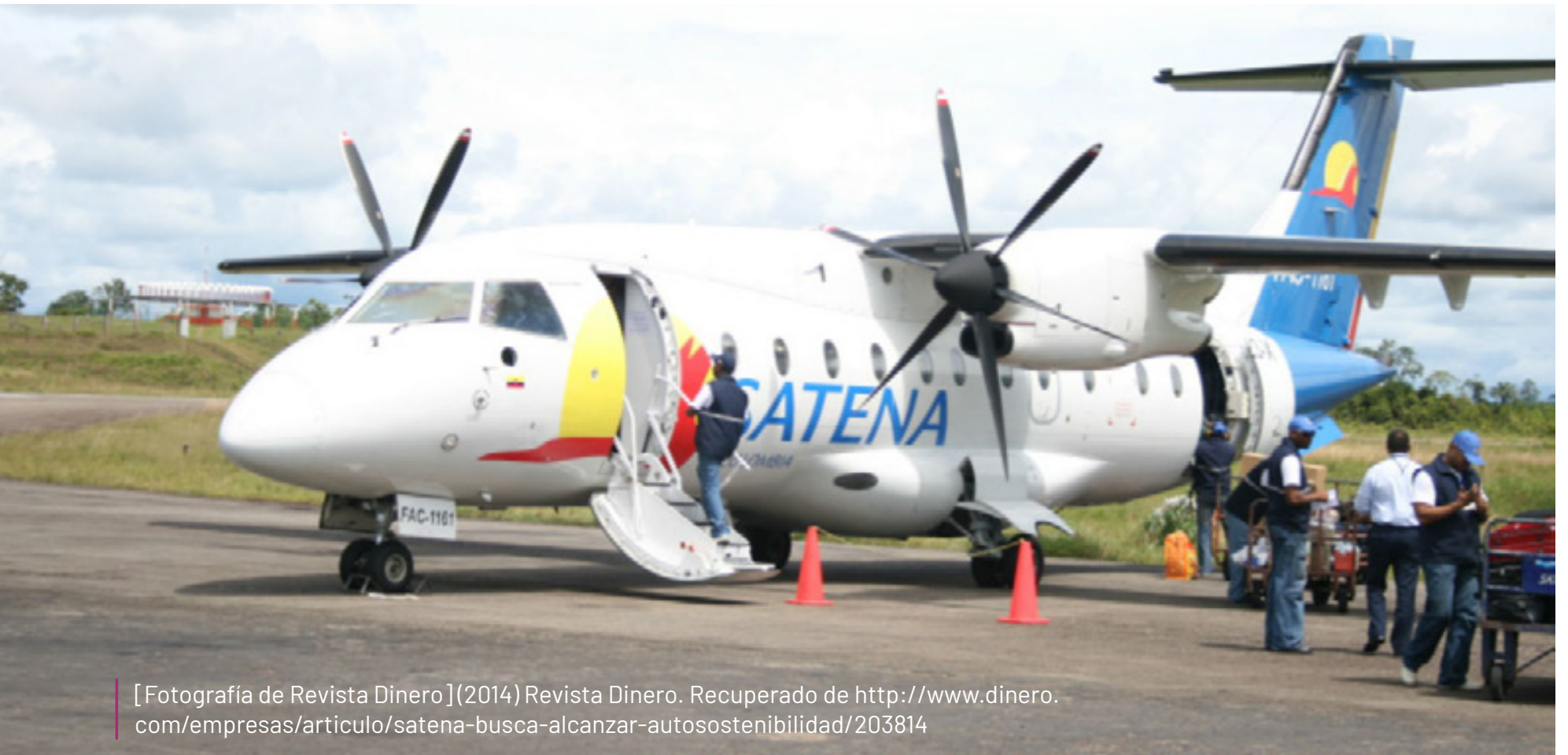

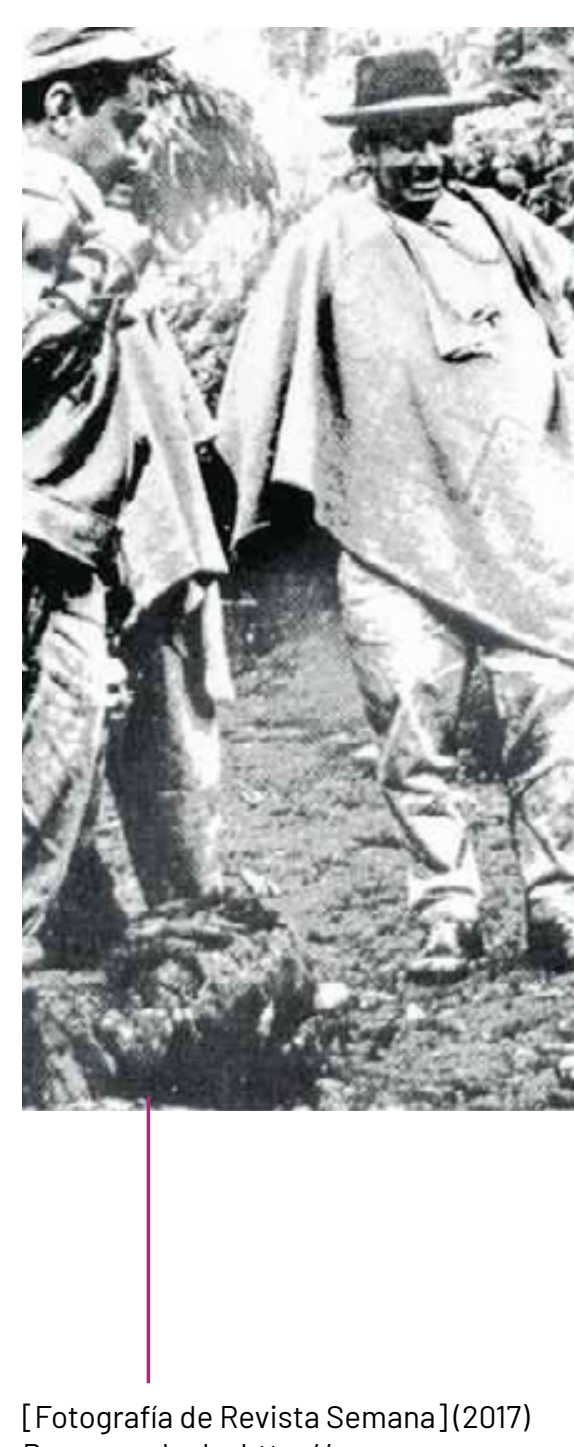

[Fotografía de Revista Semana](2017)
Recuperado de. http://www.semana. com/nacion/galeria/fotos-ineditas-de-
LA FUERZA DEL CONFLICTO Y LA FUERZA EN EL CONFLICTO

Sin embargo, el pais sufre dos grandes conmociones que pretendieron desestabilizar su modus vivendi: el paso y la conversión de las antiguas guerrillas liberales a guerrillas con talante marxista hacía inicios de la década de los sesenta, y la incursión del narcotráfico hacía finales de los años setenta. Frente a tales cuestiones, las respuestas de la Fuerza Aérea Colombiana fueron y han sido efectivas, ya que por medio de la innovación e ingenio presentes al interior de la Institución es que miles de colombianos gozan de bienestar $y$ felicidad en el seno de sus hogares.
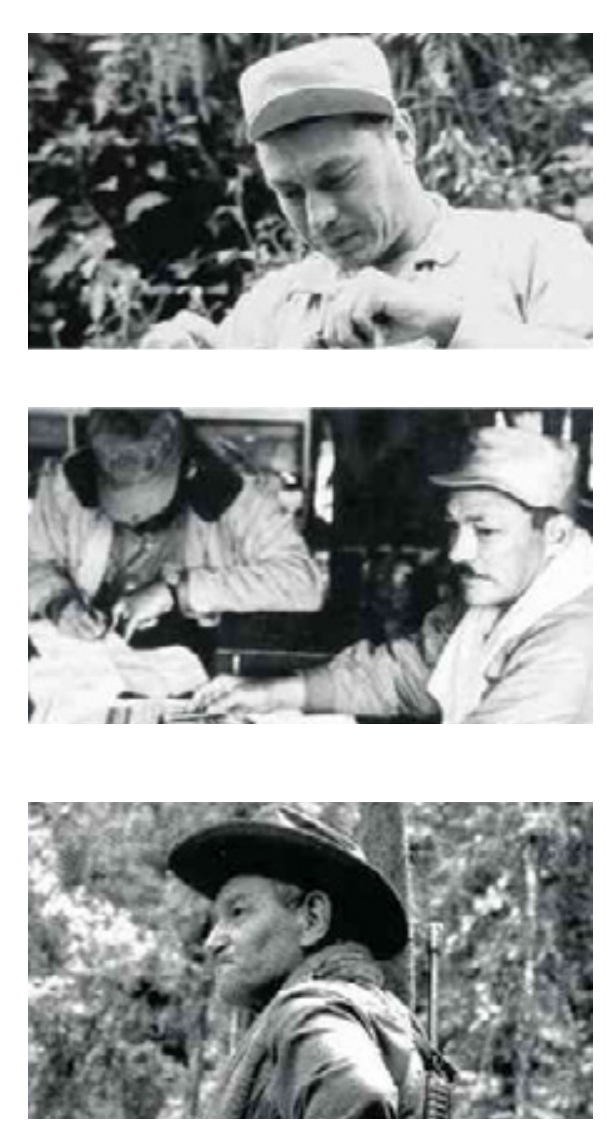

In ejemplo de lo anterior es a adaptación y desarrollo de armamento aéreo para equipos tales como el DC-3, T-37 Tweet, o UH-60L; estos llegarían a ser conocidos posteriormente como AC-47T Fantasma, OA-37B Dragonfly y AH-60L Arpía. Para el caso de este último, en los años noventa se le concibio, en primer lugar, como una aeronave de transporte, siendo el desarrollo del Arpía la consecuencia de la necesidad al interior de la Fuerza de contar con equipos que se destacaran en la lucha contra la insurgencia y la ilegalidad (Hernández, 2015, pp. 57-62), sobresaliendo operaciones tales como Vuelo de 
Ángel. Tal operación tuvo como objetivo la recuperación de la capital del Vaupés en el año 1998 a razón que Mitú habia sufrido embate de alrededor de 600 combatientes de la guerrilla de las FARC, los cuales lograron tomar casco urbano en su totalidad. Tan solo 72 horas despues de la toma ilegal, la capital del Vaupés sería efectivamente recuperada gracias al asedio realizado por la aviación militar colombiana. Con base en tal acción, se gestó como repercusión que los ataques en masa realizados por las guerrillas en suroriente del país se convirtieran en desventaja ante la capacidad de reacción y alistamiento presentes ren Fuerza Área Colombiontes anterior, es muestra plausible anterior es muestra plausible de la versatilidad y flexibilidad prela versatilidad y flexibilidad presentes a hora de la aplicación de L. 2016, pp. 23-28). al., 2016, pp. 23-28).

En esta misma línea, es que la adquisición de aeronaves tales como el A-29 Súper Tucano, han fungido un papel estratégico en la Institucion: por medio de la utillzación de los mismos es que ningún tipo de grupo armado ilegal ha podido triunfar en la realización de sus objetivos, independientemente de las perspectivas politicas o económicas que dichos puedan contener. Tales triunfos se deben a los constante procesos de aprendizaje a los que los pilotos de la Fuerza se han visto sometidos desde la creación de la misma estando respaldados sus reentre namientos en los exitosos aportes que ellos mismos han brindado en los distintos ejercicios internacionales tales como Mapple Flag de año 2013 o Green Flag de 2016.

Fue en el año 2013 donde equipos de A-29 Supertucano, KC-767 y C-130 Hércules de la Fuerza Aérea Colombiana realizaron "entrenamiento operacional en misiones aire-aire aire-tierra apoyo aéreo cercano, reconocimiento, reabastecimiento y operaciones especiales" (Fue Aérea Colombiana, 2015, párr. 1). as misiones se llevaron a cabo las misióreacaniensed Cold Lake, Caná en do Coun A-29 Supertucano cumplo 144 equipo A-2S Supertucano cumplió 144 misiones, interactuando perF-16, F-18, C-130, KC-707 y Fu, F-18, C-130, KC-767 y AWACS (Fuerza Aérea Colombiana, 2015, parr. 4). También se realizaron ejercicios con el radar de la base aerea canadiense de 4 Wing Cold Lake en donde se dispuso que dos oficiales controladores de armas de la Fuerza Aérea Colombiana hicieran parte del equipo que se encargo de guiar el ejercicio. Como complemento a tal hito, en el año 2016, 45 hombres y mujeres de la Fuerza Aérea Colombiana, con base a escuadrón A-29 Supertucano, operaron "combinadamente junto a las aeronaves estadounidenses A-10 Thunderbolt II, realizando misiones de apoyo aéreo cercano, buscando asi garantizar la supervivencia de las tropas en tierra" (Webinfomili 2016, párr. 2). Fue en la ciudad de Bossier, Lousiana, donde se reaizaron las misiones del ejercicio; allí "está ubicada Barskdale, base estrategica de la Fuerza Aérea de los Estados Unidos" (Webinfomil, 2016, párr. 4). Desde tal punto, "cuatro aeronaves Supertucano consolidaron un total de 80 horas, cumpliendo 20 misiones de apoyo aéreo cercano aplicando la Fuerza a objetivos en movimiento, operando en escenarios urbanos $y$ cumpliendo misiones unanos a pilotos eyectados, entre otras" (Webinfomil, 2016, párr. 4).

Pero históricamente, la Fuerza Área Colombiana no solo serza Aerea Colombiana no solo se ha centrado en la realización de operaciones aereas de talante militar, en donde tambien destacan las intervenciones realizadas por los recordados Mirage M- 5 de la Dassault, quienes, en companila de sus sucesores, los poderosos y modernizados cachorros de leon, los israelitas K-fir, ayudaron a recuperar grandes extensiones del territorio nacional en operaciones tales como la Operación Delta del año 2002 (Marín, et al, 2016, pp. 28-32). El excelente rendimiento de estos equipos de vuelo supersónico se ha visto reforzado por que sus pilotos han sido parte de prestigiosos ejercicios internacionales tales como Red Flag del año 2012. Dicho evento brindó entrenamiento real de combate aire-aire y aire-tierra, bajo unas condiciones seguras de operación; en el mismo se resaltó el hecho de que son pocos los paises llamados a ser partícipes de éste evento debido a los altos estándares de exigencia y calidad all establecidos:

Como parte de un paquete de los aviones K-fir apoyaron las operaciones de Búsqueda y Rescate en Combate, bombardeos a objetivos en tierra, la búsqueda de misiles SCUD, la ubicación de objetivos de alto valor y las misiones defensivas aire-aire contra aeronaves enemigas (Webinfomil, 2012, párr. 3).
Sin embargo, en la Fuerza Aérea no sólo se destacan operaciones tales como Sol Naciente, Alcatraz, Fénix, Sodoma u Odiseo, las cuales arrojaron como consecuencia el debilitamiento de las diferentes estructuras de los distintos grupos armados ilegales al golpear sus figuras de poder. Gracias a la intervención oportuna de nuestra hoy festejada Institución, es que se logró neutralizar peligrosos cabecillas insurgentes tales como alias "el Negro Acacio" y alias "Martín Caballero" en el año 2007, alias "Raúl Reyes" en el año 2008, alias el "Mono Jojoy" en el año 2010 o alias "Alfonso Cano" en el año 2011, dando así parte de victoria al cumplir su deber constitucional (Marín et al, 2016, p. 45).

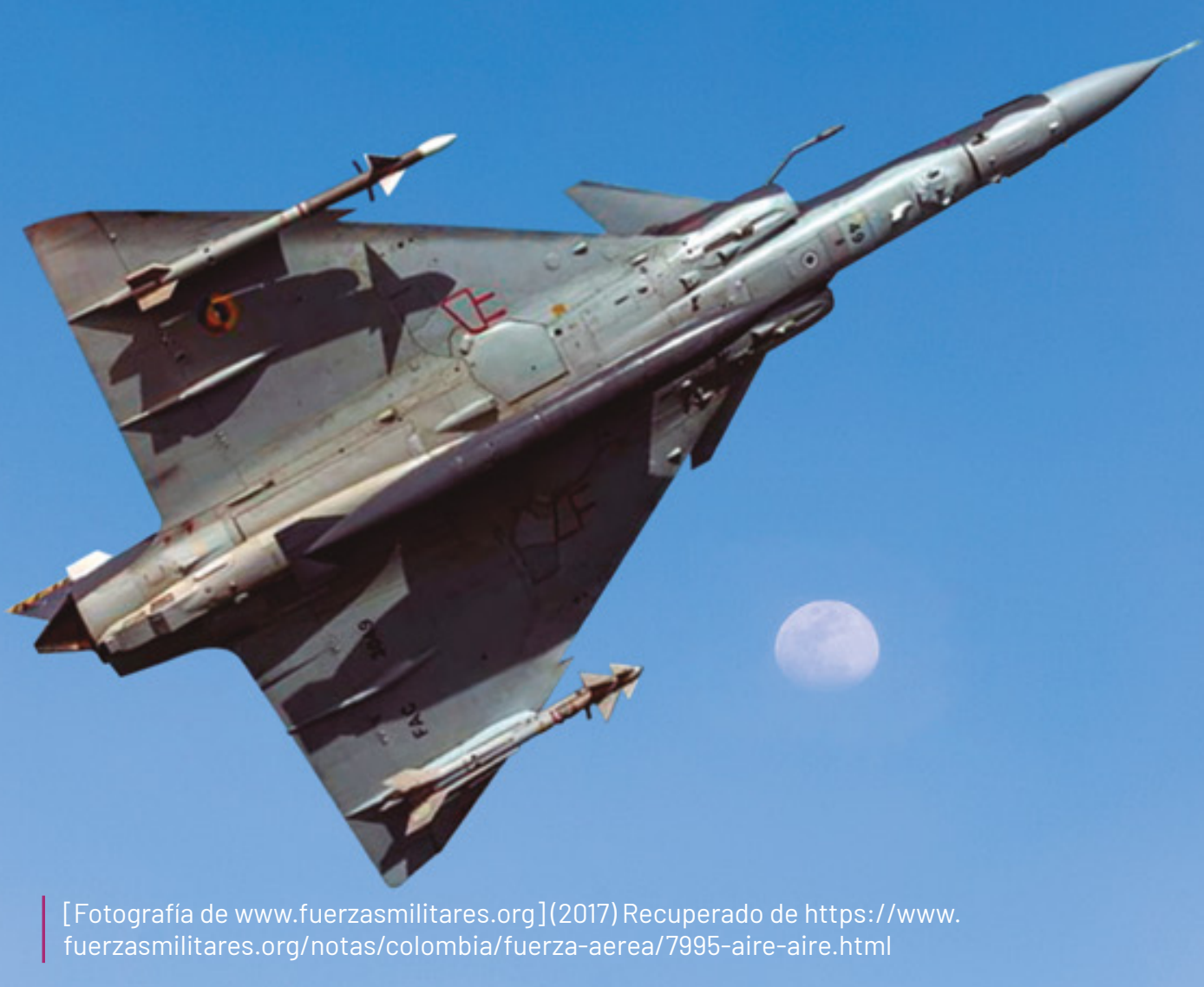




\section{FUERZA FILANTRÓPICA}

A la par, en sus cien años de historia, la Fuerza Aérea Colombiana ha realizado misiones de apoyo humanitario a todas aquellas poblaciones que se han identificado como en situación de riesgo, cruzando asi fronteras internacionales para cumplir tal objetivo. Tal es el caso de las 15 toneladas de ayuda entregadas por el avión Atlas Boeing 737 a Chile, durante el año 2015, a raíz del terremoto allí acontecido (Fuerza Aérea Colombiana, 2015, párr. 1); o las más de 30 toneladas de ayuda entregadas por el Júpiter Boeing KC-767 a Perú, durante el año en 2017, por motivo de las inundaciones ocurridas en dicho país (Fuerza Aérea Colombiana, 2017, párr. 1). sin contar las 60 toneladas de ayuda que se han transportado en los robusse han transportado en los robusficados de la trag pia le Colombiano, 2017, párr. 1).

Tales potenciales y habilidades de la Fuerza Aérea Colombiana se deben a que aeronaves como el Boeing Júpiter KC-767 y C-130 Hércules estuvieron presentes en encuentros como el Maple Flag o Cruzeiro do Sul Exercise CRUZEX, ambos de año 2013. Durante el desarrollo del primero, la aeronave $\mathrm{C}-130$ Hércules se destacó en las operaciones en las que participó como lo menciona el siguiente informe:

EI C -130 Hércules desarrolló operaciones especiales de transporte infiltración y exfiltración de tropa, seis lanzamientos de carga y 120 de paracaidistas representantes de las Fuerzas Militares de Alemania, Canadá y Colombia en las modalidades de $\mathrm{HAHO}$ (salto a gran altura con

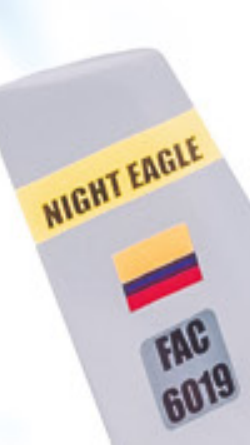

apertura a gran altura) y HALO (salto a gran altura con apertura a baja altura)(Fuerza Aérea Colombiana, 2015, párr. 5).

Por su parte, la aeronave KC-767 también demostró su destacable capacidad operacional durante el desarrollo de la versión número 46 del Maple Flag. Lo que se hace explícito en el siguiente apartado:

(...) el equipo KC -767 realizó 24 salidas que permitieron 134 conexiones de reabastecimiento en vuelo por parte de los F-18 canadienses, transfiriendo 95.000 galones de combustible bajo los estándares de operación de la OTAN (Fuerza Aérea Colombiana, 2015, párr. 6).

Por otro lado, en las bases aéreas de la Fuerza Aérea Brasileñas de Natal y Recife, la Fuerza Aérea militar Cruzeiro do Sul Exercise
[Fotografia de Erich Saumeth] (2017) Recuperado de. http:///www. opinion-aeronaves-remotamentetripuladas-colombia.php
CRUZEX. En él tomaron acción seis OA-37B Dragonfly y el KC-767, realizando "misiones de combate aireaire, aire-tierra, comando y control inteligencia, vigilancia, reconocimiento, aplicación de maniobras evasivas, operaciones especiales de transporte, capacidades de retanqueo en el equipo $767^{\prime}$ (Defensa. com, 2013, párr. 2). Todo lo anterior como lo menciona el mismo porta web, se empleo en escenarios de interoperabilidad, de acuerdo a los procedimientos establecidos en la OTAN, con el proposito de fortalecer las capacidades de las Fuerzas Aéreas Aliadas de todo el mundo (2013, párr. 2).

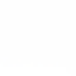

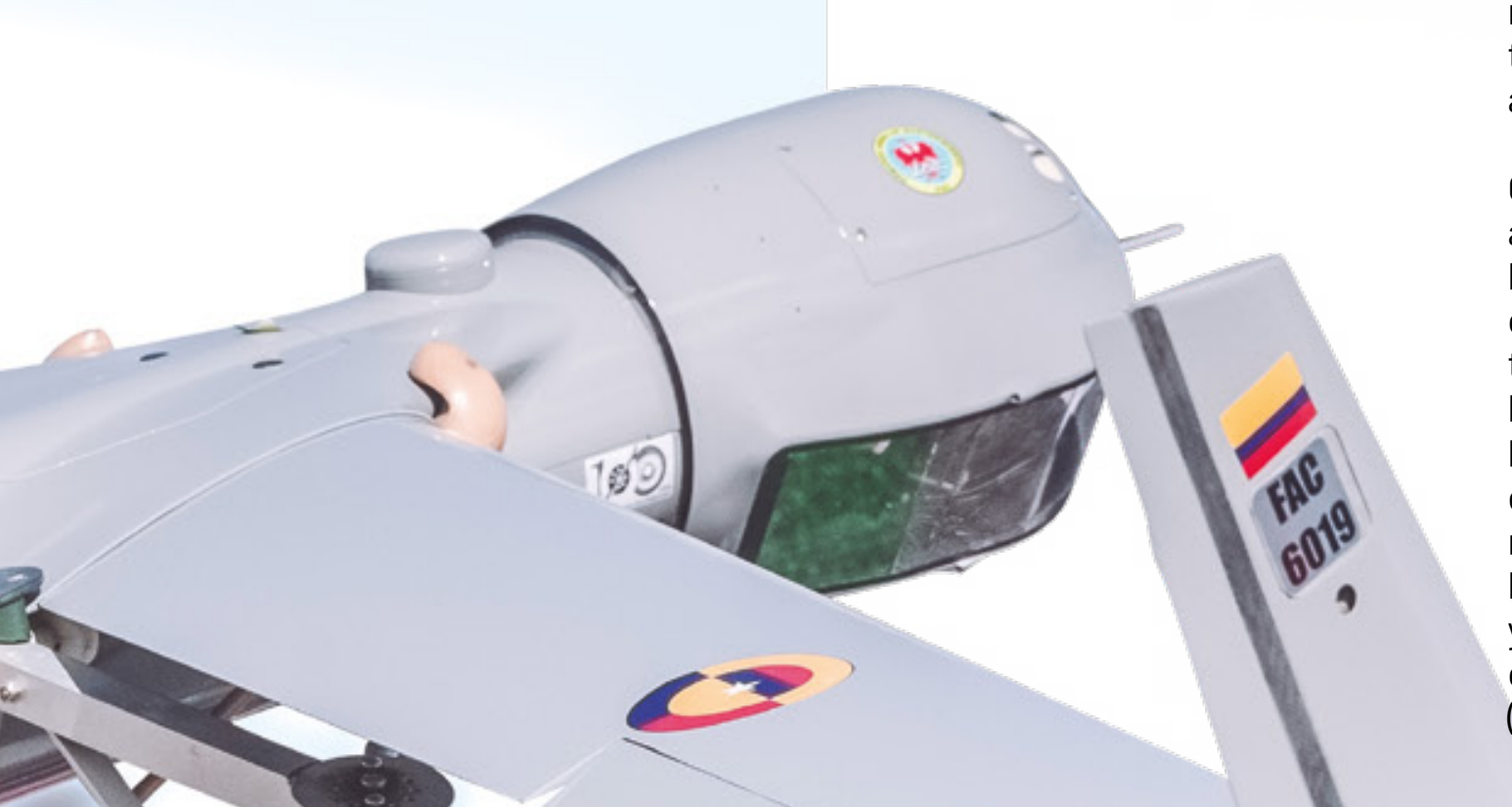

La Fuerza Aérea Colombiana también ha destacado por la gran cantidad de datos de inteligencia y vigilancia especializada que es capaz de recolectar en tiempo real. Lo anterior gracias a la puesta en operación de los ART adquiridos por la Fuerza, siendo estos equipos de vuelo ideales para labores de reconocimiento por su bajo costo de puesta en marcha, "su pequeño y sigiloso tamaño y sus grandes autonomias que les permiten estar en vuelo durante gran tiempo sobre sus objetivos sin ser detectados" (Webinfomil, 2011, párr. 2).

Además, desde la llegada de los UAV ScanEagle de la InSitu en el año 2006, los ART también se han destacado puesto que al no contar con tripulación a bordo de la aeronave, estos sobrepasan los limites de operación impuestos por el agotamiento humano.

Otra gloria de la Fuerza, y que los anales del tiempo han de enarbolar es la primera misión llevada a cabo a la Antártida. Con fines cientificos y de investigación, 13 oficiales y suboficiales dejaron abierta la brecha para "el desarrollo de estudios astronómicos, la experimentacion científica, así como el lanzamiento, recolección de datos y recuperación de elementos relacionados con el ámbito espacial" El Tiempo, 2015, párr. 5). 


\section{CONCLUSIÓN}

En pocas palabras, se puede vislumbrar que la Fuerza Aérea Colombiana es una institución de aviacion militar que en todo momento se actualiza, se proyect y se mantiene al tanto de los avances tecnologicos, que aún con cien años de historia siempre es capaz de unir y mantener todo el territorio colombiano bajo el latir de una sola bandera. Además, es capaz de acudir prontamente en ayuda de todos aquellos que lo necesitan, manteniendo siempre la soberanía de espacio colombiano y la legitimad de las leyes de la nación.
Como se evidencia a partir de las flexiones anteriormente expuesS, las capacidades que tiene el poder aereo colombiano, hasta el da de hoy, se deben en razon a que, si bien fueron distintos los momentos y circunstancias en los que surgieron, sus multiples estructuales temporales se entrecruzan constantemente en las distintas operaciones aéreas desarrolladas, elemento que ha dado resultados favorables para la Fuerza Aérea en sus tareas de defensa y protección de la nación entera. $x^{x} x$

x

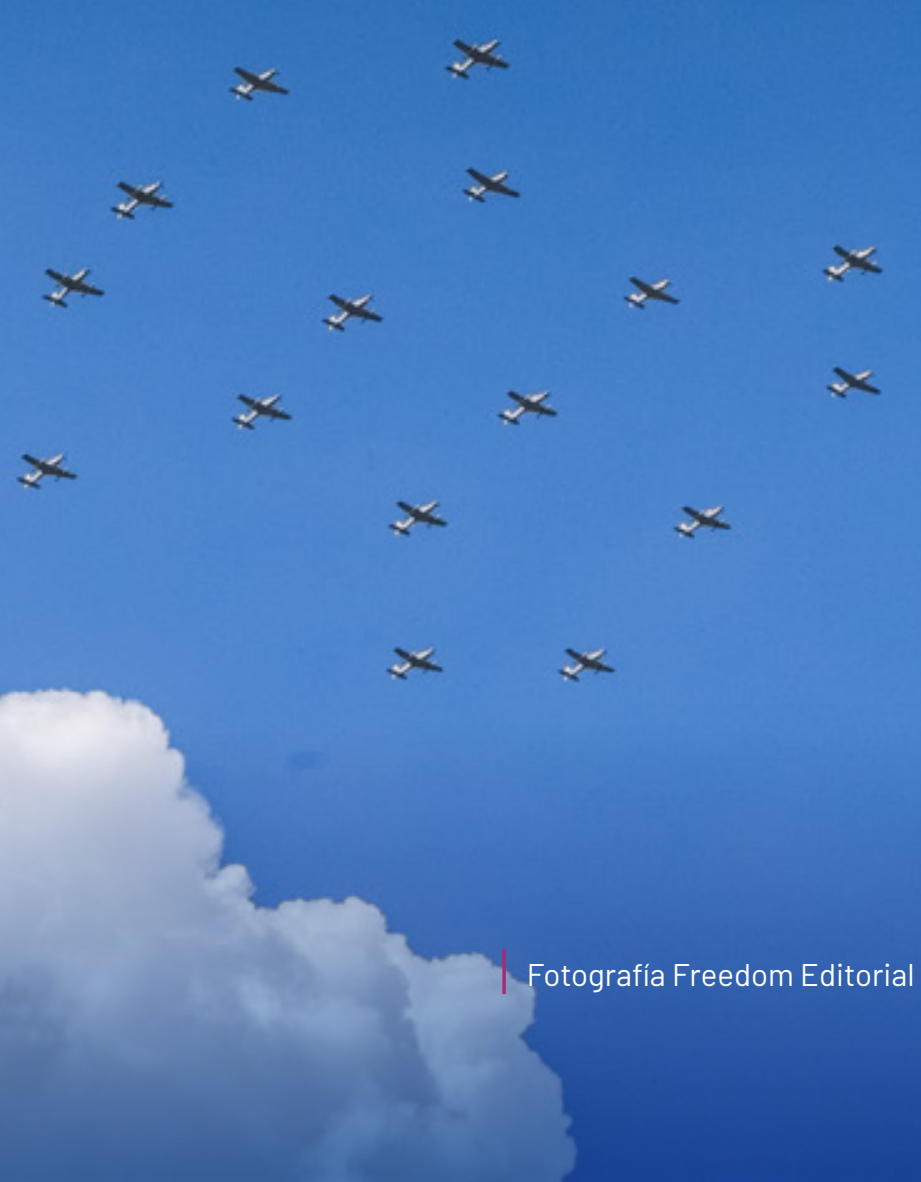

\section{REFERENCIAS}

Braudel, F. (2006). La Larga Duraión. Revista Académica de Relaciones Internacionales, (5), 1-36.

Correa, M. (4 de abril de 2017). La Fuerza Aérea ha trasladado 60 toneladas a Mocoa. El Colombiano. Recuperado de http://www. elcolombiano.com/colombia/fuerza-aerea-dia-y-noche-en-mocoa-HF6272559

Defensa.com. (29 de octubre de 2013). La Fuerza Aérea Colombiana despliega sus A-37B en el ejercicio internacional de combate aéreo "Cruzex Flight 2013", uno de los mayores en América Latina. Defensa. com. Recuperado de http://www.defensa. com/colombia/fuerza-aerea-colombiana-despliega-37b-ejercicio-internacional

[Diseño de Abraham Ortiz Miranda y Aldemar Zambrano Torres] (Bogotá D.C., 2017) Archivo de diseños digitales Escuela de Postgradic Postgrados FAC. Escuela de Postgra-

El Tiempo. (4 de febrero de 2015). Expedición de la Fuerza Aérea Colombian aterrizó en la Antártida. El Tiempo. Recuperado de http://wWW.eltiempo.

Fuerza Aérea Colombiana (2013). Manual de Doctrina Básica Aérea y Espacial (MADBA). Cuarta Edición. Bogotá: Fuerza Aérea Colombiana. Recuperado de https://avafp.blackboard.com/bbcswebdav/library/Jefatura\%20 de\%20Educaci\%C3\%B3n\%20y\%20Doctrina\%20 Militar\%20J6/4.\%20Doctrina\%20P\%C3\%BAblica/4.\%20Fuerza\%20Aerea\%20Colombiana/ Manuales/00.\%2OFAC-OE\%2OMANUAL\%20DE\%20 DOCTRINA\%2OBASICA \%2C \%20AEREA\%2OY\% 20 ESPACIAL/FAC-0-E\%20MABDA\%202013 pdF
Fuerza Aérea Colombiana. (2015). Sobresaliente participación de La Fuerza Aérea Colombiana en el Ejercicio Maple Flag 46. Recuperado de https://www.fac.mil.co/sobresaliente-participaci\%C3\%B3n-de-la-fuerza-a\%C3\%A9rea-colombiana-en-el-ejercicio-maple-flag-46

Fuerza Aérea Colombiana. (2017). Colombia envió 30 toneladas de ayuda humanitaria a Perú. Recuperado de https://www. fac.mil.co/colombia-envi\%C3\%B3-30-toneladas-de-ayuda-humanitaria-per\%C3\%BA

Fuerza Aérea Colombiana. Incorporación (2015). Ayuda Humanitaria a Chile. Recuperado de https://www.incorporacion.mil.co/ayuda-humanitaria-chile

Forero, 0. (1994). 75 Años en los Cielos Patrios. Bogotá, Colombia: Fuerza Aérea Colombiana.

[Fotografía de Erich Saumeth]. (2017). Recuperado de. http://www.infodefensa.com/ perado de. http://www.infodefensa.com/ motamente-tripuladas-colombia.php

\section{[Fotografía de Fuerza Aérea Colombiana]} (2015). Recuperado de. https://www. youtube.com/watch?v=XPL9bqDI-cM

[Fotografía de Revista Dinero]. (2014). Avión SATENA. Revista Dinero. Recuperado de. http://www.dinero.com/empresas/articulo/satena-busca-alcanzar-autosostenibilidad/203814

[Fotografía de Revista Semana]. (2017). Fotos inéditas de las FARC: 53 años en Marquetalia. Recuperado de. http://www.semana. com/nacion/galeria/fotos-ineditas-de-lasfarc-53-anos-en-marquetalia/526706 


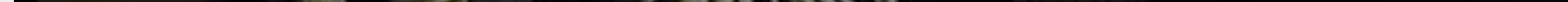

